\title{
Una literatura transatlántica (personalmente) malograda: el teatro de Paulino Masip antes y después del exilio
}

Natalia Pelaz

$\mathrm{D}$ ado el creciente interés en la llamada literatura transatlántica, la producción del exilio español republicano ha sido el blanco de muchas e interesantes aproximaciones críticas. Fuente de los más variados tópicos, la literatura de aquellos individuos o de aquellos grupos que por las condiciones históricas derivadas de la Guerra Civil produjeron en dos o más espacios nacionales sirve como punto de partida para críticos interesados en cuestiones relacionadas con lo nacional, lo cultural o lo transnacional. La gran mayoría de los estudios lidia, sin embargo, con experiencias exitosas, en las cuales el exilio no interrumpió y muchas veces hasta alimentó la creación autoral. Así, son comunes los textos sobre escritores que gozaron de éxito fuera de España. ${ }^{1}$ Estos forman parte de un revisionismo postransición, cuyo objetivo es rescatar la memoria de aquellos que se querían olvidados. Sin embargo, hay escritores que no han logrado sobrevivir impunes a la tragedia del exilio, y que han experimentado un cambio sensible

\footnotetext{
${ }^{1}$ La apreciación de la variedad, tanto en la calidad como en las perspectivas críticas y metodologías, es fácilmente observable en las actas de los numerosos congresos que ha organizado el grupo de la Universidad Autónoma de Barcelona, GEXEL, en coordinación con diferentes comunidades autónomas españolas.
} 
en su obra artística y, sobre todo, en su recepción crítica. Tal es el caso del escritor español Paulino Masip, quien pasa de la condición de dramaturgo reconocido en el mundo intelectual de los años treinta, ${ }^{2}$ a la de escritor de un sinfín de guiones comerciales para el emergente cine mexicano. Tal vez, sea esta la razón por la que su producción teatral en México quedó ensombrecida e, incluso, ignorada. Si bien se podría proponer que, dado que entre la dramaturgia y el cine las diferencias son menores que las similitudes, esta transición constituyó un hecho natural y esperable debido a la precaria situación económica derivada del exilio mismo, creo que, como explica el teórico Benedetto Croce en su Estética, "cada hecho expresivo es un individuo y sólo de un modo genérico [...] es comparable a los demás” (31).

Además, hojeando la producción literaria de Masip se llega fácilmente a la conclusión de que la mayoría pertenece al género teatral, sin embargo, los críticos que de un modo u otro se han acercado a la obra de Masip han descartado analizar estas obras. Sobra decir que, si bien se ha reeditado el conjunto de sus cuentos y su novela El diario de Hamlet García, ninguna de sus obras teatrales ha "revisitado" la imprenta. Afortunadamente, contamos con los valiosos artículos de Manuel Aznar Soler y de Irún Vozmediano, ${ }^{3}$ que analizan detalladamente cada una de las obras dramáticas de Masip pero no ofrecen una visión de conjunto, comparativa que permita discernir una evo-

${ }^{2}$ Como ejemplo, Antonio Espina, en el periódico El Sol, califica como "buena literatura” su farsa El báculo y el paraguas. Díaz-Canedo le consideró, en su tiempo, un autor que permitió formar "los mejores augurios" (El Sol, 1(1): 29) y que realzó su teatro por sus "cualidades de buen teatro en la representación" (El Sol, 31(12): 1932).

${ }^{3}$ Manuel Aznar Soler escribió "Paulino Masip, dramaturgo exiliado", incluido en las actas del congreso sobre el exilio literario español celebrado en La Rioja y que tuvo a Masip como protagonista de una de sus sesiones. Fue en esta misma sesión donde Víctor Manuel Irún Vozmediano presentó "Un acercamiento al teatro de Paulino Masip". 
lución. Es, pues, con este breve artículo, que pretendo colaborar a rellenar ese hueco.

En Madrid, el panorama teatral de la época de Masip, es decir, finales de los veinte y comienzos de los treinta, se caracterizó por su riqueza y variedad de corrientes y estilos, así como por la lucha entre los dramaturgos por hacerse un hueco en el comprimido espacio que formaban los teatros de la ciudad. Su debut teatral en la capital se debió a la ayuda inestimable de Cipriano de Rivas Cherif, quien era considerado en aquel momento como uno de los hombres de teatro ${ }^{4}$ encaminado a renovar las tablas espańolas.

En su país natal, Masip consiguió representar tres obras. La primera de ellas Dúo en 1929 y de claras reminiscencias vanguardistas tardías. La segunda, La frontera de 1932 y, por último y ya en 1936, El báculo y el paraguas. Juan Aguilera Sastre y Manuel Aznar Soler, en su libro titulado Cipriano de Rivas Cherify el teatro español de su época (1891-1967) catalogan su primera obra dentro del capítulo dedicado a los diversos ensayos para crear un teatro experimental. ${ }^{5}$ En uno de estos intentos, llamado El Caracol, cuya sede estaba en la sala Rex de Madrid, Rivas Cherif contó con la ayuda de Azorín, Valle Inclán, Manuel Azańa, Gómez de la Serna, entre otros (122). Dentro de este grupo o proyecto Masip encontró su espacio. Dúo es una pieza de un solo acto, con un escenario prácticamente vacío y cuyos personajes principales son un hombre y una mujer. El hombre es sorprendido

\footnotetext{
${ }^{4}$ Utilizo esta nomenclatura genérica ya que no se le puede definir como dramaturgo profesional, porque él no escribió obras teatrales como su modus vivendi, pero tampoco como director de escena, ya que en aquel momento no existían tales, ni como empresario teatral.

${ }^{5}$ Los autores se centran en demostrar la personalidad creadora y la pasión reformadora de Rivas Cherif. Para ello, se ofrece una explicación detallada de sus múltiples intentos renovadores, entre los que destacan los siguientes grupos: Teatro de la Escuela Nueva, Teatro Íntimo, El Mirlo Blanco, El Cántaro Roto. Todos ellos sin filiación política declarada.
} 
por la mujer en el momento en que está preparando la huida de casa. Utilizando una magistral psicología un tanto perversa, la mujer consigue convencer al hombre para que se quede en casa y acepte su superioridad intelectual, económica y social. Paulino Masip no pretende reflejar una realidad total, tal como se empeñaba la representación realista decimonónica, sino un fragmento, un pedazo aislado de esa realidad. Para conseguir este propósito, Masip deconstruye una realidad compacta para ofrecer un segmento. Esta técnica, practicada asiduamente por los artistas vanguardistas, buscaba demostrar al espectador que la realidad circundante es compleja y poliédrica. Además, supone una rebelión contra la forma de entender el mundo, la realidad, principios y los valores, bien estéticos o morales de la clase burguesa conservadora.

Víctor Manuel Irún Vozmediano ha calificado esta obra como "un auténtico banco de pruebas de lo que será su teatro posterior" (291). No obstante, si se estudia la obra dramática de Masip como un conjunto, o mejor, como una progresión, se verá que el dramaturgo evoluciona de acuerdo con la tendencia estética. Así, si en un comienzo se ha demostrado su clara filiación vanguardista, en sus obras posteriores se aprecia una suavización de los intentos renovadores. Creo que la importancia de esta pieza reside en conceptuarla como el posicionamiento ideológico de Masip dentro de las vanguardias literarias, cuando éstas ya estaban en decadencia. Lo que, desde mi punto de vista, le posiciona en una corriente cultural alternativa.

En 1932, la Compañía Dramática de Arte Moderno dirigida por Rivas Cherif representó en el Teatro Cervantes de Madrid La fronte$r a$, comedia en tres actos y en prosa. Supuso, en cuanto a la forma y al tema principal -los conflictos amorosos de dos parejas-, una retirada de los preceptos vanguardistas y un retorno a la praxis más tradicional. Sin embargo, me interesa más destacar que el tema periférico y ciertos aspectos de dos de los personajes principales se relacionan con los dramas que afectan a los individuos desplazados de su sistema 
cultural nativo, formativo. En una pensión "ranciamente castellana" (7) viven Luisa, hija de la dueña, y Mariano, pupilo. Julio y Odette son una pareja que acaba de llegar de Francia en busca de lo que ellos imaginan como "España”. Sin embargo, las estrategias para llevar a cabo esta búsqueda divergen: Julio recurre a su memoria y Odette se apoya en conceptos estereotípicos. Obviamente, ninguno de estos dos mecanismos va a producir el resultado deseado. En segundo lugar, se discute el concepto de "español". Para la francesa, Julio "no es español puro" ya que él "ve la vida como un hijo de París" (19), a lo que Mariano responde "soy español sin mezcla, de la cabeza a los pies". En el imaginario de Odette y de Mariano, la idea de mezcla intelectual adquiere una connotación negativa que disuelve la identidad nacional monolítica del individuo. La ironía de Masip alcanza su punto álgido cuando aparecen los estereotipos sobre la sexualidad. Así, Odette "orientalizando" - para utilizar la nomenclatura de Edward Said- a Mariano, es decir, imponiéndole ciertos estereotipos para ver realizados sus propios deseos, le imagina como "un marido español, celoso, orgulloso, tirano, árabe” (54).

Su última obra representada en España, en 1936, se titula El báculo y el paraguas y el mismo autor la califica como farsa. Masip erige una crítica pulida contra la hipocresía y mediocridad moral del mundo literario de la España de 1936. Pedro Díaz de Albalate representa a un escritor burgués acomodado y carente de toda voluntad, pero que ejerce su poder despóticamente en situaciones donde su superioridad es evidente, por ejemplo, frente a su secretario. Además se presenta como un individuo automarginado del acontecer público-social de 1936 por lo que, a lo largo de toda la farsa, no se hace ninguna referencia a las circunstancias exteriores a este mundillo. Los dardos de Masip también se dirigen a los críticos que tan sólo se interesan por la vida privada de los escritores y a los editores que los retrata como chantajistas. Con esta obra, no creo que Masip quisiera erigir una crítica contra el escritor autoexiliado versus el escritor 
comprometido, ya que en ningún momento se dibuja a éste como modelo. Más bien, creo que su intención es defender al escritor encerrado en su torre de marfil frente a aquel quien ha convertido la literatura en un espectáculo rosa, en una farsa. Tosquedad, popular, grotesco, bufonesco son algunos de los términos que emplea Patrice Pavis para definir la farsa (28). Son, precisamente estas características las que aplican, no a la obra, pero sí al mundo que recrea. Así pues, Masip socorre a esos intelectuales automarginados pasivos, que eran denostados e increpados por los republicanos y por gran parte del sistema intelectual. Es decir, aprovecha su posición como dramaturgo comercial para reivindicar y dar voz a unas figuras marginadas, y para cuestionar si el llamado exilio interior es una cuestión de elección o de imposición.

En estas dos últimas obras representadas, Masip recrea personajes desplazados y marginados para, de este modo, distanciarse y sentirse libre para analizar ese mundo al que sus protagonistas no consiguen adaptarse. Este desplazamiento personal permite que el personaje observe y analice el mundo con una mirada excéntrica y alternativa. Esta técnica, muy utilizada en el siglo XVIII francés por filósofos como Montesquieu (Cartas persas) y Voltaire (Cándido), no es extrańa a la literatura española y bajo la pluma de Masip tiene el poder de resurgir. Al leer estas obras de Masip se experimenta una fuerte voluntad de asociar su temática con la vida del exilio de su autor, pero nada nos lleva a verlas como un prenuncio de su futura condición. Es posible que la cuestión del exilio voluntario -pues España se ha configurado históricamente como una patria de emigrantes- haya servido de inspiración sobre todo en La frontera, por tratarse de una obra que opone el ser español a los otros ciudadanos del mundo. Asimismo, también es factible pensar que la noción de exilio interior haya jugado un papel fundamental en El báculo y el paraguas, que versa sobre la marginalidad experimentada por el individuo. Sin embargo, ninguna de las obras advierte el efecto que tendrá el exilio 
personal y real en la obra de Paulino Masip. Creo, no obstante, que es justamente el cambio de actitud del autor en las farsas lo que tal vez, más que cualquier obra suya, nos aproxime al verdadero drama de Masip como exiliado. Como resume Said, el exilio es atrayente como reflexión crítica pero es devastador como experiencia (2002: 174).

Si con la llegada de la Guerra Civil, el joven Masip todavía buscaba consolidar el reconocimiento en su tierra, la nueva condición de exiliado adquirida en México no favoreció la continuación de una trayectoria exitosa. Al igual que sucedía en España, la producción y representación teatral en México estaba condicionada por la pertenencia a un grupo, fuera éste de estudiantes, de sindicalistas o pertenecientes a alguna rama del ministerio de educación. Por otro lado, la situación política en México a la llegada de los exiliados tampoco fue de lo más propicia para su integración cultural, aunque contaron con el apoyo oficial. El sector social y cultural que era partidario de Cárdenas, también lo era de una reivindicación del componente indígena, autóctono de la cultura mexicana que obviamente excluía todo lo relacionado con España. Sobra decir que los detractores de Cárdenas, entre los que se incluían a los gachupines, se opusieron a la llegada de los republicanos a quienes identificaron con el peligro comunista. Muy interesante es analizar la bipolarización de la crítica que se encargó de estudiar este periodo del teatro mexicano. Por una parte, están aquellos que sistemáticamente rechazaban o minimizaban la influencia española en el teatro de las primeras décadas del siglo (Benavente, Arniches), tal es el caso de Magaña Esquivel; por otra, aquellos que agigantaban dicha influencia, tal es el caso de Calvo Hernando. Creo que el ambiente crítico tan dividido y el cultural tan fragmentado no favorecieron la inclusión de las producciones de españoles en los programas teatrales.

En algunas ocasiones se ha apuntado hacia la falta de un público español como la causa del fracaso del teatro español en el exilio mexicano, sin embargo creo que se ha disminuido el impacto negativo 
que tuvo la ruptura de todo un entramado de conexiones que, en última instancia, facilitaban la representación, así como la fragmentación y politización del teatro mexicano. Sin embargo, Masip intentó continuar su carrera de dramaturgo en México escribiendo dos obras teatrales, de las cuales no se tiene ninguna noticia de representación: El hombre que hizo un milagro en 1942 y El emplazado en 1949. La farsa, El hombre que hizo un milagro tiene como protagonista a Benedito, un hombre sin apenas voluntad que malvive aislado y dominado por su mujer y suegra en un pueblito castellano. Su situación se transforma radicalmente cuando acude a su barbería un ciego, quien milagrosamente recupera la vista mientras Benedito le está lavando la cabeza. A partir de ese momento, Benedito encarna a una figura mesiánica que termina demonizada por la sociedad cuando se descubre que el milagro tiene una explicación científica. Ante la presión del pueblo, tiene que huir con una mujer extranjera fascinada por su historia. La reconstrucción de Espańa y de la figura central de Benedito son las dos ideas que más me interesan destacar. Masip construye la sociedad del pueblo, sinécdoque de España, girando en torno a la violencia pasiva. Como ejemplos, Ricarda, mujer de Benedito, asegura que engañaría a su marido "¡Para vengarme, para hacerle sufrir, para que me pague la bilis que estoy tragando por su culpa! ¡Porque yo le engaño y se lo digo; claro! ¡A ver si se muere!” (22). El alguacil multa impunemente a Benedito "por pescarle los peces de colores al señor Marqués" (11) y el resto del pueblo ha condenado al ostracismo al barbero, quien sólo habla con un habitante.

Si como apunta Bettina Knapp, "vivir para dentro de uno, por la razón que sea, es exiliarse de las fuerzas de fuera, de los eventos, de las relaciones, que uno puede ver como repugnantes o difíciles" (2), ${ }^{6}$ no cabe duda de que Benedito es un exiliado en su propio pueblo. Esta

\footnotetext{
6 "To live inwardly, for whatever reason, is to exile oneself from outside forces, events, or relationships that one may find repugnant or difficult".
} 
situación cambia drásticamente cuando opera el milagro. Benedito pasa a encarnar una figura mesiánica que, hasta repite pasajes bíblicos inconscientemente, pero que es rechazada por el pueblo, sea por envidia o por miedo. Así cuando el protagonista saca unos billetes, la suegra pregunta a la mujer, "¿Te fijaste si salía humo de azufre cuando los sacaba?”(58). El alcalde, por su parte, le tilda de anarquista en un intento para desprestigiar su reputación. Ante esta situación, Benedito debe renegociar su propia identidad, ya que él se cree un elegido pero que es rechazado por su sociedad. Es gracias a Fanny, el elemento extranjero, que el barbero consigue poner fin a sus incertidumbres. Cuando se descubre que Benedito no ha realizado ningún milagro, el pueblo reacciona a la frustración "con gritos variadísimos, amenazas, injurias, insultos" (158), y Benedito y Fanny tienen que huir para salvar sus vidas. Con esta farsa, la crítica de Masip se extiende a una España eterna, mítica, cuya sociedad hipócrita, degenerada y corrompida por la sed de poder expulsa de su sistema al individuo que pacíficamente rechaza sus principios fundacionales. Una sociedad pasiva que prefiere un ídolo falso a un vacío de esperanza. Una sociedad que fuerza a la huida para sobrevivir a aquellos quienes llegaron a considerar salvadores por un momento.

En su última obra de teatro, El emplazado, farsa en tres actos, la acción transcurre en una indeterminada gran ciudad sin referencias temporales precisas. Esta imprecisión le sirve a Masip para reinterpretar irónicamente el mito de don Juan. Don Pedro se presenta como el típico tiburón de negocios, frío, egoísta, que actúa así porque no teme a la muerte. Esta actitud cambia cuando su doctor le diagnostica un cáncer terminal, agotando así sus posibilidades de un futuro glorioso. Utilizando su sexualidad para, como explica Foucault, escapar momentáneamente de la muerte, las mujeres conquistadas se suceden vertiginosamente. Al final, lejos de tener una muerte digna, como sería típico del mito, don Pedro muere atropellado por un tranvía. El aspecto que, según mi opinión, enlaza el mito de don Juan 
con el drama de los exiliados, es la reelaboración de la idea del tiempo vital. Es decir, el forzado olvido del pasado, la ausencia de futuro y el aprovechamiento hedonista del presente. Edward Said advierte que uno de los comportamientos que el exiliado puede desarrollar es "hacer un fetiche del exilio" (183) ${ }^{7}$ para distanciarse de todas sus conexiones y responsabilidades y, así, evitar el dolor que su condición crea. El crítico censura esta actitud vital porque "vivir como si todo el entorno fuera temporal pasajero y tal vez trivial, nos hace presa del cinismo petulante así como de un agresivo desamor" (183). ${ }^{8}$ Lejos de ser una solución existencial, esta necesidad vital provoca en don Pedro una lucha interior entre su yo culpabilizado católico y su yo donjuanizado. Es decir, una lucha entre su pasado y su presente, una existencia en contrapunto que le impide disfrutar totalmente del presente. Cuando el plazo se le va agotando, su yo donjuanizado va ganando la batalla y su lucha interior se aquieta. Es en este momento cuando recibe la noticia de que su diagnóstico fue un error. Pese a su arrepentimiento, Masip le niega toda posibilidad de reinserción y castiga a su donjuán con una muerte totalmente irónica. Creo que esta obra cumple dos propósitos: ofrecer un consejo a su audiencia espańola exiliada y desmitificar mediante una farsa un mito tan español como el de don Juan, que de alguna manera explica ciertos componentes de la cultura espańola que Masip rechaza.

La idea del individuo desplazado y de los mecanismos para recuperar su identidad también varían. Recordemos que en La frontera representada en Madrid, Masip lleva a las tablas la problemática generada por la memoria, el pensamiento estereotípico, la idea de identidad nacional con un sentido del humor franco, sin amargura. Ya en el exilio, el tratamiento que da a don Pedro, el protagonista de

\footnotetext{
7 "to make a fetish of exile".

8 "to live as if everything around you were temporary and perhaps trivial is to fall prey to petulant cynicism as well as to querulous lovelessness".
} 
El emplazado, dista mucho de ser paternal. Parece que la experiencia propia le hizo radicalizar su posición hacia ciertas actitudes vitales nefastas para el desplazado. Así, se podría argüir que la dificultad experimentada por el teatro de Masip en su experiencia transatlántica reside, además de en las condiciones políticas y culturales del país de exilio, en el autor mismo. Insertado en otra cultura pero reviviendo los aspectos sociales de la cultura dejada atrás, Masip fue incapaz de traducir culturalmente sus farsas. Como explica McGowan: "Firmemente situado dentro del todo social, el ser gana acceso a los códigos sociales por los cuales las identidades son constituidas $y$, a través de sus acciones, puede modelar la identidad social que él proyecta" (247). ${ }^{9}$ Incapaz de adaptarse de pleno a la sociedad adoptada y al medio literario mexicano, Masip no consigue en contrapartida proyectarse de la misma manera que hacía en Espańa. Sus farsas mordaces, y sin embargo positivas, del periodo español, se nublaron con los sentimientos de desplazamiento, de extranjería, del pasado querido al que no se puede volver. Por ello, Edward Said aclara tajantemente que los artistas del exilio son normalmente desagradables en sus obras, pues viven de la insistencia en un único asunto, el desenraizamiento que cala en sus vidas (1984: 55).

El exilio, así, afectó notablemente la producción teatral de Masip, hasta tal punto que dejó el teatro, y la literatura en general, para pasar al cine, transformándose en escritor de guiones cinematográficos. Farsas graves y de tono sombrío hacen que la diferencia más aparente y radical entre ambos periodos sea, sin duda, la posibilidad de representación. Sus obras teatrales escritas en México no fueron representadas, convirtiéndose así en un teatro para leer. Además, su situación en el exilio le llevó a transformar su método de crítica ha-

\footnotetext{
9 "Firmly situated within the social whole, the self gains access to the social codes by which identities are constituted and, through its actions, can shape the social identity it projects".
} 
cia la sociedad. Las obras escritas en España representan una crítica muy específica a un sector o a ciertos hábitos culturales. Ya en el exilio, su crítica alcanza a toda la sociedad sin excepción, llegando, incluso, a la destrucción de un mito. Tal vez esta crítica asoladora fuera consecuencia de su rechazo ante la España que quedó allá, o tal vez, sea simplemente un mecanismo para justificar su "huida". Como subraya Evelein, analizando la situación del exiliado desde la perspectiva lacaniana, el exilio significa separación, pérdida del todo y es la búsqueda de este todo perdido que pasa a transformarse en el objetivo de la escritura del exiliado (19). Siguiendo este punto de vista, podemos arriesgar que la incapacidad de reconstrucción de lo que fue perdido, que la insoportable separación de su tierra, es exactamente lo que causó que, no sólo cambiara de actitud personal, sino que, finalmente optara por un cambio radical en su producción artística abandonando completamente el teatro para dedicarse a los guiones de cine.

Así, a través de la lectura de sus farsas en conjunto, se puede observar que el exilio tuvo un fuerte impacto en la obra del dramaturgo Paulino Masip, haciendo que la carrera soñada se transformase en imposible. Él añade a su exilio personal y cultural lo que Edwards llama "expatriación poética", típica del exiliado que no consigue, a través de su literatura, dar una solución a los problemas reales derivados de la separación de la tierra (21). La distancia de la tierra lo separó de los objetos, de los tipos, de las situaciones que se le manifestaban y que encontraba idóneas para criticar, y el exilio mexicano le transformó en un ser desplazado como los personajes de sus farsas mexicanas, viviendo de un pasado para siempre perdido.

Por esto mismo, sería interesante añadir que la literatura española escrita en el exilio tiene sus peculiaridades y que son éstas las que se deben analizar para poder comprender mejor un periodo de la historia de ambos países, el de expulsión y el de recepción. No creo que sea apropiado intentar negar la existencia de dicha literatura ar- 
gumentando que no existen diferencias entre los textos escritos en el exterior y los escritos desde el exilio interior, o incidiendo en la imposibilidad de circunscribirla o encajonarla en una literatura nacional. Tanta es la diferencia entre ambas que Víctor Fuentes llega a afirmar que el exilio republicano supuso y produjo la culminación del tema España en la literatura del país (161). Así, si para muchos el exilio sirvió para que alcanzaran nuevas alturas en su escritura, para Masip, el exilio fue nefasto, transformando su literatura transatlántica en una literatura, personalmente, nada exitosa ni fructífera. Bethea, en su libro sobre Brodsky, explica que el exilio tiene muchas veces una función destructiva y paralizante, tan opresora que para tantos escritores puede transformarse en una especie de sentencia de muerte creativa (39). El exilio no cambió su talento de escritor de farsas, de dramaturgo, pero le impuso condiciones inesperadas que delinearon una diferencia extraordinaria y ostensible entre el dramaturgo Masip de antes y después del exilio.

\section{Bibliografía}

Aznar Soler, M., 2001, "Paulino Masip, dramaturgo exiliado" en Sesenta años después. El exilio literario de 1939, Universidad de la Rioja, Logroño, pp. 259-285.

y Juan Aguilera Sastre, 1999, Cipriano de Rivas Cherify el teatro español de su época (1891-1967), Asociación de Directores de Escena de España, Madrid.

Bethea, David M., 1994, Joseph Brodsky and the creation of exile, Princeton University Press, Princeton.

Croce, Benedetto, 1984, El paralelismo entre la literatura y las artes visuales, Taurus, Madrid.

Díaz Canedo, Eduardo, "Información teatral" en El Sol, 1-1-29, 4. , "Información teatral" en El Sol, 31-12-32, 4.

Espina, A., "El báculo y el paraguas, comedia en un prólogo y tres actos de Paulino Masip” en El Sol, 8-1-36, 5. 
Evelein, Johannes, 2002, "Ethics, Consciousness, and the Potentialities of Literature: Teaching Narratives of Exile" en Realms of Exile. Nomadism, Diasporas, and Eastern European Voices, Lexington Books, Lanham, pp. 15-27.

Foucault, Michel, 2005, Historia de la sexualidad, Siglo XXI, Madrid.

Fuentes, V., 2002, "Pasión y visión de España en la poesía del exilio republicano" en Letras Peninsulares 15(2), (otońo), pp. 161-174.

Irún Vozmediano, Víctor Manuel, 2001, "Un acercamiento al teatro de Paulino Masip” en Sesenta años después. El exilio literario de 1939, Universidad de la Rioja, Logroño, pp. 287-299.

Knapp, Bettina L., 1991, Exile and the Writer. Exoteric and Esoteric Experiences. A Jungian Approach, The Pennsylvania State University Press, Pensilvania.

Magaña Esquivel, A., 1964, Medio siglo de teatro mexicano, 1900-1961, Instituto Nacional de Bellas Artes, México.

McGowan, John, 1991, Postmodernism and its critics, Cornell University Press, Ithaca.

Masip, Paulino, 1929, Uno, La Farsa, Madrid.

, 1933, La frontera, La Farsa, Madrid.

, 1936, El báculo y el paraguas, La Farsa, Madrid.

, 1944, El hombre que hizo un milagro, Atlante, México.

, s.f., El emplazado, Sociedad General de Autores de México, México.

Pavis, Patrice, 1990, Diccionario del teatro: dramaturgia, estética, semiología, Paidós, Barcelona.

Said, Edward, 2002, "Reflections on Exile" en Reflections on Exile and other Essays, Harvard University Press, pp. 173-264.

, 1984, "Mind of Winter: Reflections on life on exile" en Harper's 269, 1612 (septiembre), pp. 48-59. 